\title{
Short communication: Effect of diet changes on sorting behavior of weaned dairy calves
}

\author{
J. H. C. Costa, N. A. Adderley, D. M. Weary, and M. A. G. von Keyserlingk ${ }^{1}$ \\ Animal Welfare Program, University of British Columbia, Vancouver, BC, Canada, V6T 1 Z4
}

\begin{abstract}
Dairy cows sort mixed rations; in some cases sorting can lead to digestive disorders. How sorting behavior develops in calves is poorly understood. The objective of this observational study was to determine if sorting behavior of total mixed ration (TMR)-fed dairy calves was affected by the removal of supplementary concentrate. Dairy bull calves $(n=18)$ were provided access to both a TMR (49.1\% dry matter) and calf starter fed separately during the preweaning period starting at $3 \mathrm{~d}$ of age. Sorting of the TMR was assessed after weaning when calves were provided both feeds at $65 \mathrm{~d}$ of age, and again at $70 \mathrm{~d}$ immediately following the removal of calf starter from the calf pen. Sorting was measured by comparing the particle size composition of the TMR offered with that of the orts following $24 \mathrm{~h}$ of feed access. Feed particle fractions were measured using the Penn State Particle Separator with 3 screens $(19,8$, and 1.18 $\mathrm{mm}$ ) and a bottom pan to separate the TMR into long, medium, short, and fine fractions, respectively. At d 65, calves sorted for long particles $(133 \pm 9 \%)$ and against small particles $(92 \pm 3 \%)$, with no differences for the remaining fractions $(99 \pm 5 \%$ for medium; $107 \pm 5 \%$ for fine); these preferences were reversed at d 70 when calf starter was no longer available with calves preferentially selecting fine particles (113 $\pm 4 \%)$, but showing no preference for other fractions $(101 \pm 11 \%$ for long; $99 \pm 6 \%$ for medium; $97 \pm 4 \%$ for short). These results indicate that young dairy calves are capable of sorting a TMR and they adjust this behavior in response to the availability of grain.
\end{abstract}

Key words: diet selection, ruminant, feed preference, motivation, ruminal acidosis

\section{Short Communication}

Domestic ruminants balance their intake of high-energy grain components with forage that helps buffer the rumen against the acidic byproducts of carbohydrate

Received July 2, 2015.

Accepted March 6, 2016.

${ }^{1}$ Corresponding author: nina@mail.ubc.ca fermentation (Krause and Oetzel, 2006). Unlike grazing cattle that spend between 7 and $13 \mathrm{~h} / \mathrm{d}$ grazing, adult dairy cows in intensive production systems typically spend only 3 to $5 \mathrm{~h} / \mathrm{d}$ feeding (Dado and Allen, 1994; Hosseinkhani et al., 2008). In indoor systems, both dairy and beef cattle are generally fed a TMR once or twice daily (Krause and Oetzel, 2006). The TMR generally contains forage and grain components that vary in physical (i.e., particle size) and nutritional attributes (Coppock et al., 1981). Cattle often selectively consume small, energy-dense grain particles (Leonardi and Armentano, 2003; Miller-Cushon and DeVries, 2009) when offered a TMR. Feed sorting in cattle can result in unbalanced nutrient intake and increases the risk of digestive disorders including ruminal acidosis (DeVries et al., 2008). Many studies have reported feed sorting in adult dairy cattle (e.g., Leonardi and Armentano, 2003).

Calves are also sometimes fed mixed rations, both before and after weaning from milk, but little research to date has examined feed sorting in young cattle. Consistent with the research on adult cattle, some work has found that calves will consistently sort for short particles across a range of dietary treatments (Overvest et al., 2016). However, other work has shown that sorting can be affected by dietary choices and previous experience. For example, Miller-Cushon and DeVries (2011) found that calves fed either concentrate or hay during weaning selectively consumed the familiar feed when switched to a mixed ration. Calves fed separate components (forage and concentrate) before weaning, compared with those fed a mixed ration, showed reduced feed sorting after weaning (Miller-Cushon et al., 2013). How calves are transitioned between feeds can also affect sorting. For example, a gradual dietary transition over $7 \mathrm{~d}$ resulted in more sorting compared with calves transitioned abruptly to a novel feed (Miller-Cushon et al., 2015).

Dairy calves are typically provided free access to concentrates before weaning, but in the weeks after weaning, access to supplementary concentrates is removed and the animals are often switched to a TMR. The objective of this observational study was to determine if sorting behavior of TMR-fed dairy calves 
was affected by the removal of supplementary concentrate. Removing access to supplementary concentrate increases the value of the grain that can now be only acquired through the mixed ration. We predicted that calves would show more sorting for grain within the TMR when the supplementary concentrate was no longer available.

This experiment was conducted between October 2012 and May 2013 at the University of British Columbia (UBC) Dairy Education and Research Centre in Agassiz, British Columbia, Canada $\left(49^{\circ} \mathrm{N}, 121^{\circ} \mathrm{W}\right)$. The UBC Animal Care Committee (Animal Use Protocol A12-0337) approved the procedures used in this study. All the animals were cared for according to the guidelines outlined by the Canadian Council of Animal Care (2009).

Eighteen Holstein dairy bull calves were enrolled in the study. Calves were separated from their dam immediately after birth, weighed $[44.0 \pm 6.1 \mathrm{~kg}$ of BW (mean $\pm \mathrm{SD})]$, and housed in sawdust-bedded pens $(1.2 \mathrm{~m} \times$ $2.0 \mathrm{~m})$ with no visual, but auditory contact with other calves. Within $6 \mathrm{~h}$ of birth, calves were fed by bottle at least $4 \mathrm{~L}$ of colostrum with $>50 \mathrm{~g} / \mathrm{L}$ of IgG. Serum from blood samples collected from a jugular vein $24 \mathrm{~h}$ after the first feeding of colostrum was analyzed using a Reichert AR 200 Digital Hand-held Refractometer (Reichert, Depew, NY). Only calves that had serum protein $>5.5 \mathrm{~g} / \mathrm{dL}$ were included in the study. Pens were cleaned and new sawdust replaced once per week.

Calves were bottle-fed $8 \mathrm{~L} / \mathrm{d}$ of pasteurized whole milk divided in 2 feedings, at approximately 0800 and $1630 \mathrm{~h}$ from birth until 28 d of age. From d 29 to 49, calves were fed $6 \mathrm{~L} / \mathrm{d}$, using the same procedure as described above. Milk volume was reduced by $20 \% / \mathrm{d}$ from d 50 to 55 , with milk weaning occurring on d 55 . Calves remained in the experiment until d 71. Starting at $3 \mathrm{~d}$ of age, all calves had ad libitum access to water, TMR (described in Table 1), and calf starter (Hi-Pro Medicated Calf Starter, Chilliwack, BC, Canada; Table 1). The TMR and calf starter were fed for a target orts of $1 \mathrm{~kg} / \mathrm{d}$; feeding was increased by $0.5 \mathrm{~kg}$ when orts dropped below this threshold. Over the study, TMR orts averaged ( \pm standard deviation) $1.3 \pm 0.7 \mathrm{~kg} / \mathrm{d}$ and calf starter orts averaged $1.6 \pm 0.9 \mathrm{~kg} / \mathrm{d}$. Feeding level (\% orts) was compared between test days to ensure that it was not a confounding factor, as sorting can be affect by the percentage of orts (see Miller-Cushon and DeVries, 2010). Feed refusals were removed daily before fresh feed and water delivery at approximately $0830 \mathrm{~h}$. Daily calf starter and TMR intakes were determined each morning by disappearance.

Daily representative samples of both the offered feed (taken immediately before feeding) and orts (after 24 $h$ of feed access) were taken. Sorting was assessed after weaning when calves were $65 \mathrm{~d}$ old and had access to both TMR and calf starter, and again at $70 \mathrm{~d}$ of age the first day, after which concentrate was no longer available. On both days, sorting was measured over a 24-h period. A Penn State Particle Separator with 3 screens $(19,8$, and $1.18 \mathrm{~mm})$ and a bottom pan was used to separate samples for particle size analysis into long $(>19 \mathrm{~mm})$, medium $(<19,>8 \mathrm{~mm})$, short $(<8$, $>1.18 \mathrm{~mm}$ ), and fine $(<1.18 \mathrm{~mm})$ fractions (Kononoff et al., 2003; see Table 1 for distribution of particle sizes in the TMR).

Samples for nutrient and DM analysis were ovendried at $55^{\circ} \mathrm{C}$ for $48 \mathrm{~h}$. Dried samples were ground to pass through a 1-mm screen and sent to A\&L Canada Laboratories Inc. (London, ON) for analysis of DM $\left(135^{\circ} \mathrm{C}\right.$; AOAC International, 2000, method 930.15), ADF (AOAC International, 2000: method 973.18), NDF with heat-stable $\alpha$-amylase and sodium sulfite (Van Soest et al., 1991), and $\mathrm{CP}(\mathrm{N} \times 6.25$; AOAC International, 2000: method 990.03; Leco FP-528 Nitrogen Analyzer, Leco, St. Joseph, MI).

Sorting behavior was quantified as the actual intake of each fraction (long, medium, short, and pan), expressed as a percentage of the predicted intake of each fraction (Leonardi and Armentano, 2003); the predicted intake of each fraction was calculated as the product of the DMI of the feed offered multiplied by the DM percentage of that fraction in the fed TMR. Values $>100 \%$ indicated sorting for that particle size, and values $<100 \%$ indicated sorting against that particle size.

Prior to analysis, data were screened for outliers using the UNIVARIATE procedure in SAS and probability distribution plots. All analyses were performed with

Table 1. Chemical and particle size composition of concentrate and TMR (mean $\% \pm \mathrm{SD} ; \mathrm{DM}$ basis)

\begin{tabular}{lcc}
\hline Item & Concentrate $^{1}$ & TMR $^{2}$ \\
\hline Chemical composition & \\
DM (\%) & $89.5 \pm 0.7$ & $49.1 \pm 1.5$ \\
CP (\% of DM) & $20.6 \pm 1.13$ & $16.9 \pm 0.95$ \\
ADF (\% of DM) & $7.84 \pm 0.45$ & $20.4 \pm 1.77$ \\
NDF (\% of DM) & $16.5 \pm 0.39$ & $31.8 \pm 2.68$ \\
Particles & - & \\
Long particles & - & $32.8 \pm 3.6$ \\
Medium particles & - & $37.6 \pm 3.6$ \\
Short particles & - & $13.9 \pm 1.58$ \\
Fine particles & & \\
\hline
\end{tabular}

${ }^{1}$ Hi-Pro Medicated Calf Starter (Chilliwack, BC, Canada); medicated with a coccidiostat $(50 \mathrm{mg} / \mathrm{kg}$ of lasalocid sodium).

${ }^{2}$ TMR containing $26.1 \%$ corn silage, $14.8 \%$ grass silage, $10 \%$ alfalfa hay, and $49 \%$ concentrated mix on a DM basis.

${ }^{3}$ Values obtained from chemical analysis of feed samples (A\&L Canada Laboratories Inc., London, ON).

${ }^{4}$ Particle separated, using a Penn State Particle Separator, into 4 fractions: long $(>19 \mathrm{~mm})$, medium, $(<19,>8 \mathrm{~mm})$, short $(<8,>1.18$ $\mathrm{mm})$, and fine $(<1.18 \mathrm{~mm})$. 
SAS (version 9.3, SAS Institute Inc., Cary, NC) using the calf as the experimental unit. The predicted intake of each particle size fraction, expressed as a percentage, and the relative percentage of $\mathrm{NDF}, \mathrm{ADF}$, and $\mathrm{CP}$ in the orts, were tested in both studies for a difference from 100 using $t$-tests.

At $65 \mathrm{~d}$ of age, calves preferentially sorted the TMR for long particles, consuming more of these particles than expected by chance $\left(134 \pm 9 \% \mathrm{~T}_{1,11}=3.65 ; P<\right.$ 0.01 ; Figure 1a). Conversely, calves only consumed $92 \pm$ $3 \%\left(\mathrm{~T}_{1,11}=-2.62 ; P=0.02\right)$ of the predicted intake of small particles. Intake of medium and fine particles did not differ from that predicted, with calves consuming $99 \pm 5 \%\left(\mathrm{~T}_{1,11}=-0.13 ; P=0.90\right)$ and $107 \pm 5\left(\mathrm{~T}_{1,11}\right.$ $=1.57 ; P=0.14)$ of predicted intake, respectively. At this age calves consumed the diet in such a way that no change occurred in the CP content of the TMR (106 $\left.\pm 4 \% ; \mathrm{T}_{1,11}=1.25 ; P=0.24\right)$ after $24 \mathrm{~h}$ (Figure 2 ). Likewise, $\mathrm{ADF}$ and NDF were consumed in expected proportions $\left(100 \pm 6 \% ; \mathrm{T}_{1,11}=-0.03 ; P=0.98\right.$ and 99 $\pm 4.90 \% ; \mathrm{T}_{1,11}=-0.24 ; P=0.81$, respectively $)$.

Calves $65 \mathrm{~d}$ of age showed no evidence of sorting the calf starter offered ad libitum; we also found no difference in $\mathrm{CP}\left(97 \pm 7 \% ; \mathrm{T}_{1,11}=-1.35 ; P=0.20\right)$, or $\mathrm{ADF}$ and NDF $\left(98 \pm 7 \% ; \mathrm{T}_{1,11}=-1.06 ; P=0.31\right.$ and $101 \pm$ $5 \% ; \mathrm{T}_{1,11}=0.80 ; P=0.44$, respectively), between the offered calf starter and the orts.

At d 70, when free access calf starter was no longer available, intake of fine particles exceeded the predicted value $\left(113 \pm 4 \% ; \mathrm{T}_{1,10}=3.15 ; P=0.01\right.$; Figure $\left.1 \mathrm{~b}\right)$. Consumption of large particles was as expected, with calves consuming an average of $101 \pm 11 \%\left(\mathrm{~T}_{1,10}=\right.$ $0.07 ; P=0.95)$ of predicted intake. Likewise, calves did not sort for or against medium and small particles, consuming $99 \pm 6 \%\left(\mathrm{~T}_{1,10}=0.25 ; P=0.80\right)$ and $97 \pm$ $4 \%\left(\mathrm{~T}_{1,10}=-0.68 ; P=0.51\right)$ of predicted intake of medium and small particles, respectively. At d 70 sorting was also apparent in the assessment of the dietary components of the TMR (Figure 2). Sorting decreased the $\mathrm{CP}$ content of the TMR $\left(93 \pm 2 \% \mathrm{~T}_{1.17}=-2.94 ; P\right.$ $=0.01$ ) and increased the NDF content (to $113 \pm 5 \%$; $\left.\mathrm{T}_{1,17}=2.51 ; P=0.02\right)$. Calves offered only TMR also consumed less ADF $\left(112 \pm 7 \% ; \mathrm{T}_{1,17}=1.77 ; P=0.09\right)$.

We found that calves sorted TMR for specific particle fractions. When given ad libitum access to both TMR and calf starter at $65 \mathrm{~d}$ of age, calves showed a preference for long particles consisting primarily of forage. Miller-Cushon and DeVries (2011) found that calves fed hay before weaning initially demonstrated a preference for forage particles when switched to a mixed ration containing (DM basis) 40\% hay and 60\% concentrate, but developed a preference for grain particles within 4 wk of this change in diet. An initial preference for forage has been associated with feed familiarity and devel-

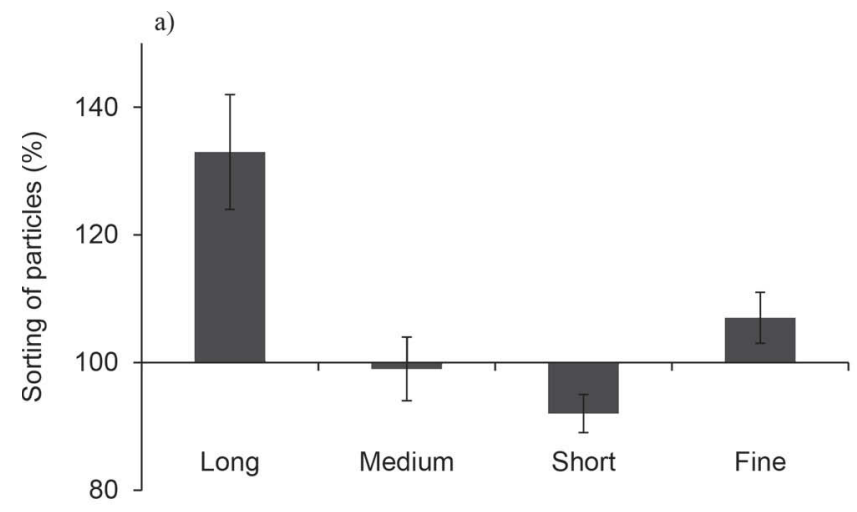

b)

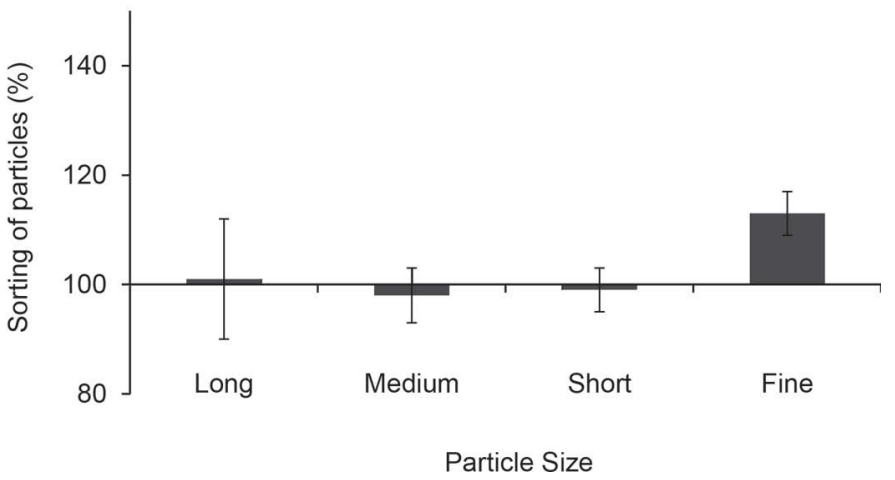

Figure 1. Mean \pm SE intake of the particle fractions of a TMR (expressed as a \% of predicted intake) when calves were offered (a) TMR and a separate grain source at $65 \mathrm{~d}$, and (b) TMR only at $70 \mathrm{~d}$. Results are from individually housed calves $(\mathrm{n}=18)$. Analyses were based upon the predicted intake of each particle fraction measured as disappearance after $24 \mathrm{~h}$ of feeding. Particles were separated into 4 fractions: long $(>19 \mathrm{~mm})$, medium, $(<19,>8 \mathrm{~mm})$, short $(<8,>1.18$ $\mathrm{mm})$, and fine $(<1.18 \mathrm{~mm})$.

oping sorting skills (Miller-Cushon and DeVries, 2011). However, unlike those in Miller-Cushon and DeVries (2011), calves in the present study were fed TMR from birth, so it is unlikely that their sorting behavior was due to feed neophobia or a lack of the requisite motor skills to obtain fine particles.

Overvest et al. (2016) found that calves fed only TMR since birth demonstrated no sorting behavior at 9 and 11 wk of age. The DM percentage and nutritional analysis show that the TMR fed by Overvest and colleagues was similar to that provided calves in the current study. The main difference between these studies was that calves in the present study were fed concentrate in addition to the TMR, which we suggest motivated the calves to sort for long particles.

Our results are consistent with some earlier findings. For instance, Forbes and Kyriazakis (1995) found that sheep consumed an appreciable amount of forage when offered a choice between forage and concentrate. Because ruminants are believed to learn through physi- 


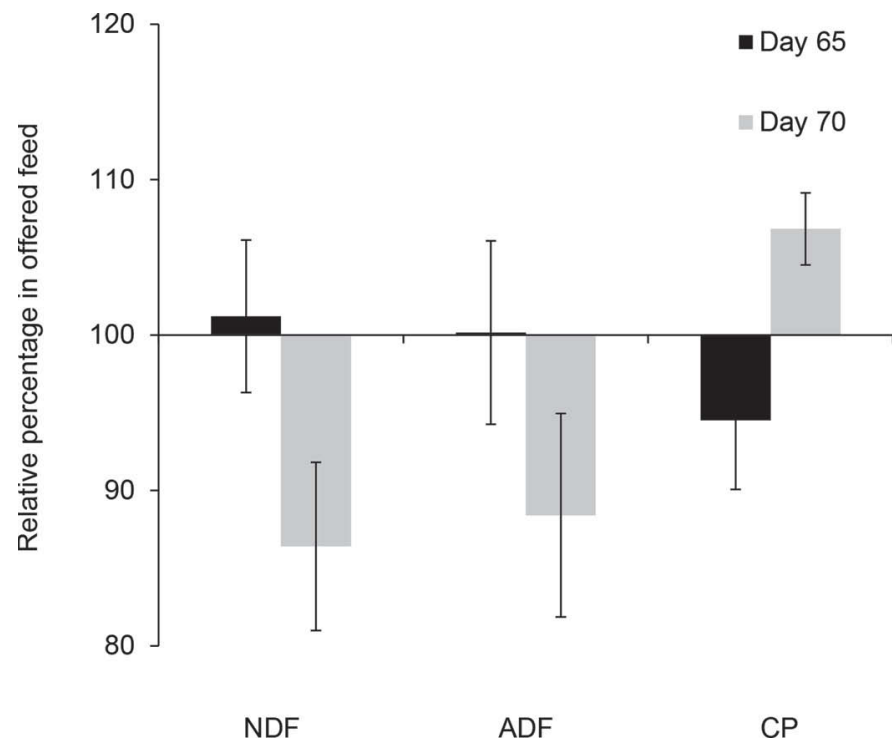

Figure 2. Mean $\pm \mathrm{SE}$ of NDF, ADF, and CP in the TMR fed to calves compared with orts. Results are for individually-housed calves $(\mathrm{n}=18)$ provided access to TMR and concentrate at $65 \mathrm{~d}$, and TMR only at $70 \mathrm{~d}$.

ological postingestive feedback mechanisms (Provenza, 1995), our results suggest that calves fed both a TMR and free choice calf starter from birth learn to balance consumption of grain and forage in ways that mitigate the effects of lower rumen $\mathrm{pH}$.

Following the removal of free-access calf starter, at the age of $70 \mathrm{~d}$, calves modified their sorting behavior, preferentially sorting for fine particles in the TMR. Orts were also lower in $\mathrm{CP}$ and higher in $\mathrm{ADF}$ and $\mathrm{NDF}$, relative to the fed TMR. Preferential consumption of fine, high-energy particles has been reported in previous studies on cows (Leonardi and Armentano, 2003; DeVries et al., 2008). DeVries and von Keyserlingk (2009) also reported that young dairy heifers sorted for concentrate when offered concentrate and hay or when concentrate was top-dressed on the hay. This type of sorting is expected to maximize the energy intake (Provenza and Balph, 1987; Hughes, 1993), so young calves may also be expected to prefer grain particles to hay when presented with a choice (Webb et al., 2014a).

In this study, we only noted sorting for grain within the TMR when the supplementary grain source was removed. Another study found that sorting behavior in calves may depend on availability of other feed sources, as calves selected the diet for forage before weaning and for the grain portion of the diet after weaning (MillerCushon et al., 2013). Together, these results indicate that calves are able to vary their investment in sorting behavior depending upon the accessibility of other sources providing the same nutrients. We argue that these findings suggest that ruminants are able to make dietary choices from a young age, and these choices are driven by nutritional demands, rumen function, or their motivation to chew and ruminate.

Although calves sorted the TMR during the study, they did not appear to be able to sort the calf starter. Given that the calf starter was provided as a pellet, it is not surprising that the calves were not able to sort for specific components within the calf starter. In contrast to texturized calf starter, pelleted calf starter has been suggested to decrease sorting behavior (Hutjens, 2001; Moran, 2012), although to our knowledge no research has specifically addressed this issue.

The current study has several limitations. The design of the current study followed normal calf rearing procedures, with calves initially provided free access to starter and then transitioned to a mixed diet with forage. However, this design confounds diet with age, and thus it is possible that some of the changes in sorting we observed were due to calves being 70 versus $65 \mathrm{~d}$ old. Future studies could apply a switch-back design (with calves again provided concentrate in a third phase of the test) to rule out developmental effects.

In the current study, sorting behavior was estimated from a single 24 -h period for each dietary phase (i.e., at d 65 and 70 only). Given that sorting can vary on a day-to-day basis, future work should include a larger number of sample days to more accurately characterize sorting within each of these 2 phases. However, because of differences in the birth dates of the different calves used in this study, data collection was always on different days for different calves, so day-to-day variation in TMR composition or other factors present in the current study should not introduce a systematic bias and would likely affect both treatments equally.

The results from the present study showing that calves select forage from a mixed diet suggest that calves are motivated to access forage in early life. Provision of forage to young dairy calves has long been controversial, due to the concerns that it may displace concentrate intake and thereby impair rumen development (Hill et al., 2008). Many calves are not provided access to forage until they are completely weaned from milk, leaving concentrate as the only source of solid feed before weaning (Kertz et al., 1979). The results from the current study, and those from Miller-Cushon et al. (2013), together with experimental work showing that calves will perform an operant task to access forage (e.g., Webb et al., 2014b), suggest that calf welfare would be improved by providing calves access to forage early in life (see review by Khan et al., 2016).

Although sorting is not conventionally considered as a way of assessing feed motivations, we argue that sorting can be viewed as a naturalistic method to judge how hard ruminants will "work" to access dietary com- 
ponents. We encourage future work to compare this naturalistic approach with more traditional methods of testing motivation in animals.

We conclude that calves can use sorting to preferentially select for either long or short particles in a mixed ration, depending upon the availability of other feeds. We also suggest that sorting for longer particles indicates that calves are motivated to consume forage when provided free access to concentrate.

\section{ACKNOWLEDGMENTS}

We thank Heather W. Neave, Tracy A. Burnett, and Jennifer Black (UBC), and Ajmal Khan (Ag Research, New Zealand) for their comments on previous drafts of this manuscript. We also thank the staff and students of the UBC Dairy Education and Research Centre who helped in this experiment, especially Eraldo Drago Filho, Rebecca Meagher, and Tatiane Camilotti (UBC Animal Welfare Program) for their help with data collection. J. H. C. Costa was supported by a scholarship from CNPq, Brazil. M. A. G. von Keyserlingk and D. M. Weary are supported by Canada's Natural Sciences and Engineering Research Council (NSERC) via Discovery grants and via the Industrial Research Chair Program with industry contributions from the Dairy Farmers of Canada (Ottawa, ON, Canada), British Columbia Dairy Association (Burnaby, BC Canada), Westgen Endowment Fund (Milner, BC, Canada), Intervet Canada Corporation (Kirkland, QC, Canada), Zoetis (Kirkland, QC, Canada), Novus International Inc. (Oakville, ON, Canada), BC Cattle Industry Development Fund (Kamloops, BC, Canada), Alberta Milk (Edmonton, AB, Canada), Valacta (St. Anne-deBellevue, QC, Canada), and CanWest DHI (Guelph, ON, Canada).

\section{REFERENCES}

AOAC International. 2000. Official Methods of Analysts. Vol. I. 17th ed. AOAC International, Arlington, VA.

Canadian Council on Animal Care. 2009. CCAC Guidelines on: The Care and Use of Farm Animals in Research, Teaching and Testing. Ottawa, Canada.

Coppock, C. E., D. K. Bath, and B. Harris Jr.. 1981. From feeding to feeding systems. J. Dairy Sci. 64:1230-1249.

Dado, R. G., and M. S. Allen. 1994. Variation in and relationships among feeding, chewing, and drinking variables for lactating dairy cows. J. Dairy Sci. 77:132-144.

DeVries, T. J., F. Dohme, and K. A. Beauchemin. 2008. Repeated ruminal acidosis challenges in lactating dairy cows at high and low risk for developing acidosis: Feed sorting. J. Dairy Sci. 91:39583967.

DeVries, T. J., and M. A. G. von Keyserlingk. 2009. Short communication: Feeding method affects the feeding behavior of growing dairy heifers. J. Dairy Sci. 92:1161-1168.

Forbes, J. M., and I. Kyriazakis. 1995. Food preferences in farm animals: Why don't they always choose wisely? Proc. Nutr. Soc. 54:429-440.
Hill, T. M., H. G. Bateman, J. M. Aldrich, and R. L. Schlotterbeck. 2008. Effects of the amount of chopped hay or cottonseed hulls in a textured calf starter on young calf performance. J. Dairy Sci. 91:2684-2693.

Hosseinkhani, A., T. J. Devries, K. L. Proudfoot, R. Valizadeh, D. M. Veira, and M. A. G. von Keyserlingk. 2008. The effects of feed bunk competition on the feed sorting behavior of close-up dry cows. J. Dairy Sci. 91:1115-1121.

Hughes, R. N. 1993. Diet Selection: An Interdisciplinary Approach to Foraging Behavior. Blackwell Scientific Publications, Cambridge, MA.

Hutjens, M. 2001. Successful Feeding Systems for Dairy. W. D. Hoard \& Sons Company, Fort Atkinson, WI.

Kertz, A. F., L. R. Prewitt, and J. P. Everett. 1979. An early weaning calf program: Summarization and review. J. Dairy Sci. 62:18351843.

Khan, M. A., A. Bach, D. M. Weary, and M. A. G. von Keyserlingk. 2016. Invited review: Transitioning from milk to solid feed in dairy heifers. J. Dairy Sci. 99:885-902. http://dx.doi.org/10.3168/ jds.2015-9975.

Kononoff, P. J., A. H. Heinrichs, and D. R. Buckmaster. 2003. Modification of the Penn State forage and total mixed ration particle separator and the effects of moisture content on its measurements. J. Dairy Sci. 86:1858-1863.

Krause, K. M., and G. Oetzel. 2006. Understanding and preventing subacute ruminal acidosis in dairy herds: A review. Anim. Feed Sci. Technol. 126:215-236.

Leonardi, C., and L. E. Armentano. 2003. Effect of quantity, quality, and length of alfalfa hay on selective consumption by dairy cows. J. Dairy Sci. 86:557-564.

Miller-Cushon, E. K., R. Bergeron, K. E. Leslie, G. J. Mason, and T. J. DeVries. 2013. Effect of early exposure to different feed presentations on feed sorting of dairy calves. J. Dairy Sci. 96:4624-4633.

Miller-Cushon, E. K., and T. J. DeVries. 2009. Effect of dietary dry matter concentration on the sorting behavior of lactating dairy cows fed a total mixed ration. J. Dairy Sci. 92:3292-3298.

Miller-Cushon, E. K., and T. J. DeVries. 2010. Feeding amount affects the sorting behavior of lactating dairy cows. Can. J. Anim. Sci. 90:1-7.

Miller-Cushon, E. K., and T. J. DeVries. 2011. Effect of early feed type exposure on diet-selection behavior of dairy calves. J. Dairy Sci. 94:342-350.

Miller-Cushon, E. K., J. P. Vogel, and T. J. DeVries. 2015. Short communication: Feed sorting of dairy heifers is influenced by method of dietary transition. J. Dairy Sci. 98:2687-2692.

Moran, J. 2012. Rearing young stock on tropical dairy farms in Asia. CSIRO Publishing, Collingwood, Australia.

Overvest, M. A., R. Bergeron, D. B. Haley, and T. J. DeVries. 2016. Effect of feed type and method of presentation on feeding behavior, intake, and growth of dairy calves fed a high level of milk. J. Dairy Sci. In press.

Provenza, F. D. 1995. Postingestive feedback as an elementary preference and intake in ruminants determinant of food. J. Range Manage. $48: 2-17$.

Provenza, F. D., and D. F. Balph. 1987. Diet learning by domestic ruminants: Theory, evidence and practical implications. Appl. Anim. Behav. Sci. 18:211-232.

Van Soest, P. J., J. B. Robertson, and B. A. Lewis. 1991. Methods for dietary fiber, neutral detergent fiber and monostarch polysaccharides in relation to animal nutrition. J. Dairy Sci. 74:3583-3597.

Webb, L. E., B. Engel, H. Berends, C. G. van Reenen, W. J. J. Gerrits, I. J. M. de Boer, and E. A. M. Bokkers. 2014a. What do calves choose to eat and how do preferences affect behaviour? Appl. Anim. Behav. Sci. 161:7-19.

Webb, L. E., M. B. Jensen, B. Engel, C. G. van Reenen, W. J. Gerrits, I. J. de Boer, and E. A. Bokkers. 2014b. Chopped or long roughage: What do calves prefer? Using cross point analysis of double demand functions. PLoS ONE 9:e88778. 